\title{
Publisher Correction to: Optimization of butt welding of zinc-coated thin sheets with oscillating fiber laser beams: weld formation, microstructure, and mechanical properties
}

\author{
Zhenghao Zhang ${ }^{1,2} \cdot$ Yan Zhao ${ }^{1} \cdot$ Shikai Wu ${ }^{1,2} \cdot$ Hongtao Lu ${ }^{3}$
}

Published online: 10 August 2021

(c) International Institute of Welding 2021

\section{Publisher Correction to: Welding in the World \\ https://doi.org/10.1007/s40194-021-01162-8}

Due to a mistake during production the publication of this article unfortunately contained a mistake. The legends of Fig. 9-12 were not correct, please see the correct legends below.

Fig. 9 a Welded joint macro-morphology before salt spray corrosion. $\mathrm{b} \mathrm{Zn}$ distribution before salt spray corrosion. c $\mathrm{Fe}$ distribution before salt spray corrosion. $\mathrm{d}$ Welded joint macro-morphology after salt spray corrosion. e Zn distribution after salt spray corrosion. $\mathrm{f} F e$ distribution after salt spray corrosion

Fig. 10 a,b Macro-morphology of welded joints after corrosion. c,d Corrosion product morphology. e XRD analysis of corrosion product
Fig. 11 The non-oscillating and oscillating welding beam paths and welding areas

Fig. 12 The effect of the oscillating beam on the elimination of pores in the weld

The original article has been corrected.

Publisher's note Springer Nature remains neutral with regard to jurisdictional claims in published maps and institutional affiliations.

The original article can be found online at https://doi.org/10.1007/ s40194-021-01162-8.

Shikai Wu

wushikai@bjut.edu.cn

1 Institute of Laser Engineering, Faculty of Materials and Manufacturing, Beijing University of Technology, Beijing 100124, China

2 Shanghai Institute of Optics and Fine Mechanics, Chinese Academy of Sciences, Shanghai 201800, China

3 Cangzhou Houtall Intelligent Equipment Co., Ltd, Cangzhou 061600, Hebei, China 